\title{
Processos de ensinagem em desenvolvimento local participativo ${ }^{1}$
}

\author{
Teaching-learning in the participatory local development
}

\section{Processus d'apprentissage dans participatif de développement local}

\author{
Procesos de enseñanza y aprendizaje en desarrollo local participativo
}

\author{
Ricardo Lopes Correia ${ }^{2}$ \\ Samira Lima da Costa ${ }^{2}$ \\ Marco Akerman ${ }^{3}$
}

Recebido em 15/03/2017; revisado e aprovado em 19/04/2017; aceito em 26/04/2017

DOI: http://dx.doi.org/10.20435/inter.v18i3.1526

\begin{abstract}
Resumo: Este artigo tem por objetivo compreender as apreensões sobre questões de vida local como conteúdo do conhecimento nos processos de ensinagem em desenvolvimento local participativo. Trata-se de uma pesquisa documental resgatada durante atividades de extensão universitária num bairro de assentamento no interior de São Paulo. Compreendeu-se que esse processo permite uma triangulação de elementos para a desconcentração de capitais e a produção de outras epistemologias entre ciência e cotidiano.
\end{abstract}

Palavras-chave: desenvolvimento local; ensino e aprendizagem; rede de apoio; terapia ocupacional; território.

Abstract: This article aims to understand the concerns about local life issues as critical content in the training of undergraduate students. This is a documentary research rescued during university extension activities in a settlement neighborhood in the interior of São Paulo. Teaching-learning-work proposals were developed based on teaching processes in participatory local development.

Key words: local development; teaching and learning; support network; occupational therapy; territory.

Résumé: Cet article vise à comprendre les préoccupations des problèmes de la vie locale comme contenu essentiel dans la formation des étudiants des cycles supérieurs. Ceci est une recherche documentaire rançonné pour les activités de vulgarisation de l'université dans un quartier de colonisation à São Paulo. propositions d'enseignement-apprentissage-travail ont été développés soutenue dans les processus d'enseignement et d’apprentissage dans le développement local participatif.

Mots-clés: developpement local; enseignement et d'apprentissage; reseau de soutien; ergotherapie; territoire.

Resumen: Este artículo tiene como objetivo comprender las preocupaciones de los temas de la vida local como contenido crítico en la formación de los estudiantes en graduación. Se trata de una investigación documental rescatados para las actividades de extensión universitaria en una zona de asentamiento en São Paulo. Propuestas de enseñanza-aprendizaje-trabajo se desarrollaron sostenidas en los procesos de enseñanza y aprendizaje en el desarrollo local participativo.

Palabras clave: desarrollo local; enseñanza y aprendizaje; red de apoyo; terapia ocupacional; territorio.

\section{INTRODUÇÃO}

Quais são os processos de ensino-aprendizagem envolvidos nas ações em desenvolvimento local?

Este artigo trata sobre os processos, os paradigmas e as atividades que possibilitam pensar o campo educativo do desenvolvimento local, a partir de experiências em extensão universitária, como um locus do conhecimento entre universidade e diversos outros segmentos da sociedade.

\footnotetext{
${ }^{1}$ Resultados parciais da pesquisa de doutorado do primeiro autor, "Processos de ensinagem em desenvolvimento local participativo: a articulação comunitária e produção do conhecimento fronteiriço enquanto capital social". O projeto foi aprovado pelo comitê de ética da Faculdade de Medicina do ABC, sob o parecer no 1.516.433, de 27 de abril de 2016.

${ }^{2}$ Universidade Federal do Rio de Janeiro (UFRJ), Rio de Janeiro, Brasil.

${ }^{3}$ Universidade de São Paulo (USP), São Paulo, Brasil.
} 
Coloca-se como hipótese de que a produção de conhecimento é um valor educativo, e que os caminhos para a sua produção permitem a tomada e ampliação de consciência crítica de agentes locais, sobre os modos de engajamento em atividades cotidianas para o enfrentamento das questões de vida local.

Com isso, esta pesquisa toma como recorte a dimensão da vida local, compreendida como a rede de microrrelações sociais intimamente ligada a dimensão das questões globais.

A partir da visão epistemológica do campo das Ciências Sociais em desvelar compreensões sobre as diversas realidades, menos avaliativas e, sim, mais compreensivas, utilizou-se a pesquisa documental para resgatar registros de memórias sobre os processos de ensino-aprendizagem-trabalho de um projeto de extensão universitária em desenvolvimento local participativo no município de Itapeva, interior do estado de São Paulo.

O objetivo deste artigo é compreender as apreensões sobre questões de vida local como conteúdo do conhecimento nos processos de ensinagem em desenvolvimento local participativo.

As conclusões sugerem que esses processos de ensino-aprendizagem-trabalho, paradigmas e atividades podem ser pistas para aquilo que identificamos como comunidades.

\subsection{Ensinagem e paradigmas do desenvolvimento}

Ensinagem é o termo cunhado por Léa das Graças Camargo Anastasiou em 1994, para se referir a uma prática social, crítica e complexa em educação entre professor e estudante, "englobando tanto a ação de ensinar quanto a de apreender" (ANASTASIOU; ALVES, 2004, p. 15), dentro ou fora da sala de aula.

Trata-se de um processo interativo, dialógico e participativo, como campo propício às metodologias ativas (SILVEIRA; RIBEIRO, 2005), ancorados na Teoria da Educação de Paulo Freire.

A ensinagem enquanto processo de ensino-aprendizagem abandona a ideia de "dar aulas" para dar lugar ao "fazer aulas" num sentido de trabalho real, in loco (ANASTASIOU; ALVES, 2004, p. 15). A partir da relação professor-estudante se estabelece um contrato ético-didático, em que são criadas estratégias para a aproximação de conteúdos contextualizados na realidade social. Esse conjunto permite a produção de conhecimento engajado e híbrido, entre o acadêmico e o cotidiano.

O "fazer aulas" visa superar os tradicionais modelos e métodos de ensino sustentados no Ratio Studiorun 4 , as aulas expositivas e palestras, com o qual o ensino superior já se acostumou.

Com a era tecnológica, as pessoas estão cada vez mais informadas e portando tecnologias de acesso à informação. Com isso cabe uma necessária problematização, pois transmitir informações, como já afirmava Freire (2011), não sustenta o real papel do ensino e do professor. Estes, devem produzir algum tipo de processo crítico à realidade e desvelar as suas camadas de sentidos, gerando novos e significativos conhecimentos.

Anastasiou (2005) propõe que o professor seja um estrategista, no sentido literal do termo, aquele que irá de forma potente e criativa explorar os meios e as condições favoráveis da realidade, visando à apreensão de conteúdos sustentados pelos valores e especificidades dos conteúdos em que estes estão inseridos.

\footnotetext{
${ }^{4}$ Modelo de ensino praticado pelos jesuítas nos primeiros anos após o descobrimento do Brasil, que consistia em expor conteúdos avaliar a capacidade de memorização destes (ANASTASIOU; ALVES, 2005).
} 
As estratégias são meios, como recursos, técnicas, atitudes e atividades que farão a mediação, a aproximação e a tomada de percepção do estudante sobre os conteúdos da realidade.

Já os conteúdos, para a autora, são grandes campos do conhecimento que expressam as dinâmicas da vida social, formações de forças, redes e capitais significados por determinados segmentos da sociedade. Os conteúdos permitem a inserção e aplicação de tecnologias que irão inferir transformações e manutenções no tecido social. Portanto possuem uma forma própria para a sua apreensão, pois são contextualizados na história e na cultura local.

Assim, o processo de ensinagem é uma triangulação, que a autora denomina como "momentos" (ANATASIOU, 2005, p. 16), em que o professor triangula o fazer aulas, a criação de estratégias e o imergir dos estudantes na realidade própria dos conteúdos.

Aproximando a concepção de ensinagem aos paradigmas do desenvolvimento, compreende-se que neste último, seus paradigmas determinaram e determinam modos de compreensão e transformação sobre a vida, uma vez que seus conteúdos vividos, em redes de relações microssociais, são importantes marcadores para os tipos e os modos de fazer projetos que coloquem o desenvolvimento enquanto paradigma.

A relação entre universidade e dimensões da vida local, expressas pelas estruturas e dinâmicas de identificação e pertencimento de agentes de diversos segmentos na vida cotidiana, possibilita pensar a extensão universitária, como um elemento do tripé universitário ${ }^{5}$, enquanto loco fundamental para a produção de conhecimentos mais críticos dos sujeitos envolvidos, assim como de transformações da realidade.

A extensão universitária ao proporcionar a comunicação-ação entre instituição de ensino superior e outros segmentos da sociedade, retoma com o estudante a criticidade de seu papel profissional, imerso em um contexto do qual ele nunca saiu, mas que passou a ser significado cientificamente como outro lugar, geralmente chamado de comunidade ou sociedade, como se estes fossem outro universo, não o mesmo que a própria conjuntura da universidade ${ }^{6}$.

Historicamente a universidade se legitimou como lugar de produção do conhecimento. Atualmente não é mais possível apartar a dimensão social, em seu sentido amplo e plural, das expressões e modos de ser e operar na universidade. Os conhecimentos, as epistemologias da vida social, são expressões que devem ser reconhecidas pela Universidade, como um sistema complexo de aproximações e distanciamentos dos seus diversos segmentos, assim como, determinantes de suas próprias produções epistemológicas (BOURDIEU, 2004).

A vida cotidiana é tomada muitas vezes na literatura científica, em especial as das Ciências Sociais, como a vida simples, popular ou do senso comum, hierarquizando as formas de aprendizagem sobre o mundo e nivelando as inteligências. O desafio como colocado por Freire (2011), Anastasiou (2005) e Bourdieu (2004) é que essas ambivalências e dicotomias possam ser superadas e que um melhor e maior aproveitamento desse sistema complexo possa ser útil socialmente à própria ciência, como a ciência possa ser útil à sociedade.

As mudanças e os efeitos cada vez mais acentuados dos fluxos globalizantes do capitalismo, colocaram em tensionamento a produção dessas epistemologias plurais, dando lugar à lógica

\footnotetext{
${ }^{5}$ Tripé ensino-pesquisa-extensão.

6 “A Extensão Universitária, sob o princípio constitucional da indissociabilidade entre ensino, pesquisa e extensão, é um processo interdisciplinar, educativo, cultural, científico e político que promove a interação transformadora entre Universidade e outros setores da Sociedade" (FORPROEX, 2012, p. 16).
} 
da flexibilização financeira, o especialismo e a produção de tecnologias duras como formas de sobrevivência e legitimação na sociedade atual (BOURDIEU, 2004).

A ciência como expressão acadêmica, portanto, atividade da Universidade, passou a produzir profissionais e pesquisadores distantes do tecido social, portadores de um conteúdo abstrato e flexível, de interesses globalizantes e financeiros. A realidade tornou-se mais objeto de estudo do que conteúdo do saber científico engajado.

Dos anos de 1970 até aqui, em todo o mundo, os processos econômicos centralizaram modelos de desenvolvimento e qualidade de vida. Verificou-se uma série de processos de ruptura e acentuações da pobreza, do desemprego estruturado, dos inválidos necessários à máquina econômica e assistencialista, assim como a forte divisão e escalonamento entre nações desenvolvidas, em desenvolvimento e subdesenvolvidas (FÉLIX et al., 2009), que expressam em suas dinâmicas processos de concentração de capitais.

Para Bourdieu (2004) a ideia de capital representa a produção e a divisão da materialidade e imaterialidade no campo das forças humanas e sociais. Torna-se uma questão do capital, quando há desproporções dessa produção e divisão.

Assim, é possível dizer que, dessa conjuntura somada à corrida do ensino superior em oferecer respostas à sua manutenção ou avanço, gerou-se uma série de técnicos sob a lógica desenvolvimentista-econômica. A extensão, como percurso de formação universitária, historicamente reside nessa lógica.

Um exemplo evidente é quando os critérios da "aplicação" das atividades extensionistas são os de estender suas ações para "comunidades carentes". O termo traz expressões atribuídas a certo grupo de pessoas, localizadas em um determinado espaço geográfico, que estão incluídas marginalmente no vazio da produção econômica e que, portanto, são "incapazes" de ascender às esferas de desenvolvimento e à produção de outros capitais como o social, intelectual, cultural etc.

A estigmatização desses grupos populacionais produz uma cultura de valorização da pobreza e da vida cotidiana como objeto útil à ciência, como afirma Valladares (2005), pois, por meio destes, é que parcela das Ciências pode continuar respondendo a sua função social, se distinguindo hierarquicamente das demais camadas da sociedade.

Amartya Sen (2000), ao questionar esses pressupostos e a dinâmica social estabelecida pelos indicadores econômicos, compreendeu que, distante de negá-los, seria necessário o desenvolvimento de novas formas mais justas e equânimes para que a grande quantidade de pessoas nas zonas marginalizadas experimentassem suas liberdades, apreendendo capitais que as tornassem capazes de levar a vida conforme as razões que fossem justas para si.

A Teoria das Capacidades, desenvolvida por Sen (2000), em seu sentido geral, compreende a produção de possibilidades substanciais às pessoas como ação do Estado, gerando acesso à dimensão pública local e global, para que as pessoas possam experimentar liberdades individuais e coletivas.

Desde 1970, o marcador que incidiu forte expressão sobre a organização social e os seus processos de mudança em nível micro e macrossocial foi a lógica do desenvolvimento. Não à toa que uma extensa literatura, em especial a dos anos de 1990, como afirma Ribeiro (2005), reporta conceitos, práticas e debates adjetivando o desenvolvimento como econômico, social, local, participativo, sustentável, comunitário, cultural, territorial e tantos outros.

Podemos compreender, assim, que o marcador "desenvolvimento" coloca a preocupação mundial sobre as dinâmicas e transformações do sistema capitalista e do papel do Estado em propor soluções aos seus efeitos perversos nas expressões da vida humana. 
Sem a pretensão de abrir um extenso debate sobre as teorias do desenvolvimento e suas adjetivações, é necessário aqui entendê-las como perspectivas e paradigmas, que atuam como pontos de partida e recortes da realidade que orientam determinadas práticas sociais.

Elegeu-se, nesse quadro teórico, o desenvolvimento local participativo (DLP), como portador do paradigma da participação enquanto capital social, que, segundo Morais e Callou (2017), Barros e El-Deir (2012), Félix et al. (2009) e Ávila (2008), funciona como uma abordagem educativa na realidade, em que a participação é o meio e o fim para o desenvolvimento de capitais significados na esfera humana coletiva, possibilitando a construção e as transformações de um local de pertencimento e produção de liberdades.

A participação, nesse sentido, é a capacidade dos agentes de um determinado local engajarem-se consciente e ativamente nas questões e atividades de seu dia a dia (FÉLIX et al., 2009), territorializados e contextualizados pelas características, atributos, especificidades e dimensões do local, compreendidos, segundo Correia e Akerman (2015) e Akerman (2005), como a dimensão cultural e geográfica percebida e vivida cotidianamente.

Para Somekh (2008, p. 21), cada vez mais se aposta na ideia de que ações políticas, em todos os seus sentidos, são mais bem operacionalizadas em âmbito local, uma vez que expressam as dinâmicas e estruturas globais do desenvolvimento e que, portanto, as inferências no local alteram o global, e vice e versa - dimensão "glocal".

Sendo assim, se uma das chaves de compreensão da realidade social global reside no desenvolvimento, enquanto conjunto de questões de ordem histórica, política e social, como apontam Somekh (2008) e Bourdieu (2004), entende-se que a dimensão local é reciprocamente portadora das mesmas chaves de questões, tendo, no entanto, outras redes de significações, sentidos e estruturas de expressão e enfrentamento.

A busca pela criação de mecanismos de enfrentamento dessas questões é o trabalho de qualquer movimento engajado, como aquele que esperamos no papel das universidades. E, portanto, lançamos a hipótese de que processos de ensino-aprendizagem-trabalho como naturezas do trabalho acadêmico possam ser caminhos que corroborem com respostas a essa problemática.

Entende-se que a investigação sobre as produções de significados e sentidos sobre a vida local e suas questões de desenvolvimento são conhecimentos relevantes no que se coloca aqui como processos de ensino-aprendizagem nas dimensões da vida local.

Sugerimos, a partir de diversas experiências em campo, com projetos de extensão em desenvolvimento local participativo, a possibilidade de pensar sobre conteúdos de apreensão do conhecimento relacionados às questões de vida local, ou seja, expressões de vulnerabilidades e marginalizações vividas em redes de relações microssociais.

Foi a partir da quantidade de documentos produzidos dessas experiências de extensão universitária que compreendemos um fio condutor de processos de transformações de diversos locais de atuação com estudantes de diferentes cursos junto a organizações da sociedade civil e do poder público.

Esse fio condutor é o que chamamos de ensinagem em desenvolvimento local participativo. Um processo de ensino-aprendizagem colocado em trabalho para a construção de conhecimentos em projetos participativos ao desenvolvimento local. 


\section{OS CAMINHOS DA PESQUISA}

Trata-se de uma pesquisa documental ${ }^{7}$, no campo das Ciências Sociais, em que foram resgatados e analisados registros descritivos e imagéticos da experiência de extensão universitária entre seis instituições de ensino superior junto ao Projeto Rondon ${ }^{\circledR} \mathrm{SP}^{8}$.

Os documentos registraram memórias sociais dos processos de ensinagem em desenvolvimento local participativo em um bairro de assentamento, Jardim Kantian, localizado no município de Itapeva, região sudoeste do estado de São Paulo, durante sete dias consecutivos em julho de 2015.

Os documentos selecionados foram um relatório final elaborado por estudantes (ITAPEVA, 2015), que contemplam descrições das experiências vividas entre os dias 10 e 17 de julho de 2015, e um diário de campo remissivo do coordenador da equipe, professor de Terapia Ocupacional. 0 relatório foi construído em conjunto por estudantes dos cursos de Enfermagem, Administração em Comércio Exterior, Nutrição, Fisioterapia e Medicina.

Os documentos foram lidos, organizados em um texto narrativo (PIMENTEL, 2001) e extraídas frases e palavras de conteúdo, a partir dos procedimentos técnicos de Análise de Conteúdo (BARDIN, 2016): Análise de Enunciação- palavras-chave que enunciavam a triangulação de ensinagem em DLP apreendidas pelos estudantes. A técnica de Análise de Correlações- aproximação das palavras-chave em unidades de conteúdo.

O diário de campo remissivo do professor foi utilizado para contextualizar as informações entre uma experiência e outra. Por fim, geramos categorias de análise tratadas sobre o quadro teórico proposto.

\section{AS MEMÓRIAS DOS PROCESSOS DE ENSINAGEM EM DESENVOLVIMENTO LOCAL PARTICIPATIVO}

As memórias são narrativas sobre as percepções da realidade e os documentos são uma das fontes que registram tais eventos.

Após sucessivas leituras do documento (ITAPEVA, 2015), as informações foram organizadas em um texto narrativo, como orienta Pimentel (2001), respeitando a temporalidade dos eventos, seu conteúdo e contexto, de modo que as memórias registradas pudessem conduzir por si só a construção de um quadro de investigação. Dessa forma, a narrativa abaixo é a transcrição dos registros documentais que foram contextualizadas, a partir do diário remissivo.

O bairro Jardim Kantian foi fundado e reconhecido pela prefeitura de Itapeva em 2002, com apenas três moradores, que já ocupavam a área localizada próximo ao bairro Jardim Bela Vista desde o início de 1990, anteriormente conhecido por Jardim Santa Luzia, nome que homenageava uma santa.

\footnotetext{
${ }^{7}$ A pesquisa documental possui enquanto objeto e campo de estudo o documento (PIMENTEL, 2001).

${ }^{8}$ O Projeto Rondon Nacional, criado em 1966, deixou de ser política pública em 1989, retomando suas atividades em 2004, a partir do movimento da União Nacional de Estudantes (UNE) e hoje mantém apoio do Ministério da Defesa (DE) (SAPPI, 2006). No entanto, o Projeto Rondon ${ }^{\circledR}$ SP foi criado como uma associação sem fins lucrativos. Durante o período de extinção do Rondon Nacional, possuía os mesmos objetivos: desenvolver ações a nível local nas áreas de saúde, cidadania, educação, social e meio ambiente, junto a Instituições de Ensino Superior parceiras, no entanto suas ações se restringem ao estado de São Paulo e não recebem apoio do governo federal (Antônio Bongiovanni, coordenador do Projeto Rondon ${ }^{\circledR} \mathrm{SP}$ )
} 
Não há informações oficiais nem entre os próprios moradores do porquê de o bairro ter passado a se chamar Kantian, no entanto é assim que é nomeado até hoje, fazendo parte das memórias de pouco mais de 230 famílias ${ }^{9}$.

O primeiro contato com os moradores se deu em julho de $2013^{10}$, por meio de uma assistente social coordenadora do Centro de Referência em Assistência Social - CRAS, do município de Itapeva.

A informação que tivemos do CRAS era que se tratava de um "bairro carente", que, por possuir um histórico de "ocupação ilegal"11, muitos problemas ocorriam, como, a desorganização de moradias. Após a legalização do uso do espaço pela prefeitura, houve um crescente e expressivo número de famílias, "gerando" conflitos entre vizinhos, violência, tráfico de drogas e trabalho infantil.

A assistente social nos informou também que havia uma importante e conhecida liderança no bairro chamada Deniro ${ }^{12}$. Pedimos para a assistente social nos apresentar a ele, pegamos um carro da prefeitura, e fomos em direção ao bairro, paramos em frente à Associação de Moradores, no mesmo quintal em que ficava a casa de Deniro.

A partir do contato com Deniro, ele nos apresentou o bairro e outros moradores mais ativos nas atividades da associação, participamos de algumas atividades locais ${ }^{13}$ estabelecendo vínculos com as pessoas.

Deniro nos informou sobre as atividades e necessidades do bairro e dos projetos que já estavam em andamento, como: projeto de uma horta comunitária, reformas estruturais da creche local, ampliação da cozinha do PETI, da secretaria de assistência social e a criação de uma fábrica de tijolos para que os moradores pudessem construir suas casas.

A necessidade emergente era ausência de lazer e área para a prática esportiva. O bairro possuía um campo de futebol, que estava em péssimas condições, localizado numa área destinada a loteamento.

Nesse mesmo dia, Deniro nos apresentou Joaquim (Quinca ${ }^{14}$ ), que era a única pessoa que tratava da questão do esporte na Associação de Moradores, cuidando de um time de futebol masculino, apenas para adultos.

Reunimo-nos ao final do dia com a equipe geral do projeto ${ }^{15}$, os estudantes foram convidados pelo professor a apresentarem suas impressões pessoais sobre o local, debatendo de

\footnotetext{
${ }^{9}$ Essas informações foram coletadas a partir das narrativas de Deniro, liderança do bairro.

${ }^{10}$ As atividades de extensão no município de Itapeva se iniciaram em julho de 2011, contemplando diversos outros bairros, porém somente em julho de 2013 tivemos a oportunidade de inserção no Jardim Kantian.

${ }^{11}$ Colocamos entre parênteses as duas expressões, a fim reforçar as representações sociais atribuídas à determinados grupos estigmatizados socialmente. No entanto, não iremos tratar destas representações neste trabalho. Para maiores informações sobre as representações sociais à grupos estigmatizados ver Valladares (2005).

${ }^{12}$ Todos os nomes que aparecem durante o trabalho são nomes reais e possuem ciência informada em termo de "Condições de uso de som e imagem" do Projeto Rondon ${ }^{\circledR}$ SP, que cedeu autorização para a pesquisa e divulgação.

${ }^{13}$ Os moradores nos convidaram para participar de uma missa católica na casa de uma das moradoras, em outra tomamos café da tarde, participamos de uma atividade junto a crianças acompanhadas por um programa do CRAS chamado PETI, ajudamos um grupo de moradores a descarregar caminhonetes com tambores de tomates vindos da horta comunitária, brincamos na rua com as crianças, entre muitas outras.

${ }^{14}$ Durante os registros ora aparece como Joaquim ora como Quinca, sendo a mesma pessoa.

${ }^{15}$ Durante a realização desta atividade havia outros estudantes envolvidos, orientados por outros professores, desenvolvendo atividades em outros bairros. Entretanto, ao final de cada dia, fazíamos uma reunião geral para que os estudantes pudessem compartilhar entre si as experiências que estavam sendo construídas.
} 
que maneira poderiam criar e propor estratégias para que os conteúdos apreendidos fossem transformados em questões e objetivadas em um projeto de ação.

Acordou-se que o objetivo de nossas ações deveria estar em torno do lazer do bairro. Para isso seria importante explorar as percepções sobre essa questão junto aos demais moradores, uma vez que era algo enunciado a partir das experiências e percepções da liderança, e as percepções dos moradores poderiam ser bem distintas, gerando outros rumos ao projeto.

Elaboramos então entrevistas domiciliares, que contemplassem a problemática do lazer e do esporte no bairro, com questões simples e objetivas. Em seguida, tabularíamos os dados e solicitaríamos uma roda de conversa com os moradores, a ser feita na própria Associação de Moradores, para compartilhar as informações produzidas e mediar a construção de um projeto de lazer local.

Para essa tarefa com os estudantes, o professor utilizou uma lousa para a construção de um brainstorm ${ }^{16}$. Organizou as ideias em pequenos blocos para orientar a tomada de decisão entre os estudantes e ao final foi feita uma reflexão sobre a decisão tomada.

A proposta não era criar somente um levantamento de dados e informações estatísticas, mas sim, utilizar a estratégia de entrevistas para explorar percepções entre os moradores sobre a realidade do lazer no bairro e, a partir destas, gerar novas estratégias em torno de um projeto de vida coletiva. Feitas nossas decisões de atuação em equipe, no dia seguinte levamos a proposta das estratégias para Deniro.

Chegamos à Associação de Moradores e apresentamos as propostas de estratégias para Deniro e Quinca, que se mostraram entusiasmados, reconheceram a importância do apoio prestado e nos disseram sobre um vereador que já havia prometido apoio com as questões do bairro. Quinca também nos convidou para assistirmos a um jogo de futebol do campeonato da cidade de Itapeva, que ocorreria no mesmo dia, num campo próximo ao bairro. Disse que seria importante conversarmos com os organizadores e verificar a possibilidade de colaboradores.

Com isso, verificamos a percepção de Deniro e Quinca sobre a necessidade de formação de redes de apoio para o projeto local. Sugerimos a roda de conversa como estratégia para apresentar o projeto a outros moradores e convidar o vereador e demais representantes do poder público local.

Em seguida, fomos ao jogo e tivemos a oportunidade de conhecer o Gaiola, um rapaz que era responsável pelo campo e que contou a história de construção daquele local com o envolvimento de moradores e apoio da prefeitura para alguns materiais.

A conversa com Gaiola possibilitou um momento de trocas de conhecimentos e modos de operar projetos coletivos entre sociedade civil e poder público, o que nos ajudaria a pensar o projeto do jardim Kantian, a partir de saberes e experiências locais.

No terceiro dia, fomos logo pela manhã realizar as entrevistas. Durante o dia todo nos organizamos em duplas e passamos de casa em casa, com a ajuda de Deniro, que auxiliava nos aproximando de maneira menos formal com os moradores.

No bairro havia 158 casas, e foram feitas as entrevistas em 113 delas. Não determinamos a quantidade de pessoas entrevistadas, aproveitamos aqueles moradores que estavam presentes e dispostos.

Constatamos que, das 113 famílias do Jardim Kantian, 106 informaram que a prefeitura não oferecia opções de lazer e que para 78 famílias o lazer era importante para a qualidade de vida,

\footnotetext{
${ }^{16}$ Chuva de ideias.
} 
divertimento e segurança do bairro. As principais percepções informadas pelas famílias sobre o que elas queriam de lazer estiveram relacionadas a equipamentos de lazer, 61 das famílias gostariam de uma praça com equipamentos ao ar livre e pista para caminhada, 26 desejavam um parquinho com brinquedos para crianças, e 21 gostariam de quadra e campo para a prática de esportes diversos.

Durante as entrevistas, perguntávamos qual seria a melhor forma de experimentar o lazer e quais estratégias poderiam ser utilizadas para que os desejos e concepções de todos pudessem ser contemplados. Os moradores relatavam a importância da construção de um espaço com função social mais ampla, a fim de proporcionar integração entre as pessoas de todas as faixas etárias, com opções de divertimento, incentivo à prática esportiva, além de tornar o bairro mais atraente, valorizando esteticamente o local.

Embora toda a população mostrasse interesse por uma área de lazer, mais da metade dos entrevistados relatou também o desejo de implantação de uma unidade de saúde e de uma escola no bairro, já que a população precisava se deslocar até outro bairro para utilizar desses serviços. Explicamos que poderia ser o projeto de lazer uma primeira experiência de construção comunitária e que as demais questões e demandas que fossem percebidas pelos moradores, com a organização deles, poderiam ser discutidas e encaminhadas junto à Associação de Moradores. Ao final de cada entrevista, convidávamos os moradores para a roda de conversa, deixando um bilhete com as informações do dia e horário.

Por meio das entrevistas, conhecemos Dener, um jovem formado em Educação Física, que dava aulas de futebol para as crianças do Jardim Kantian e que apresentava interesse em contribuir com as questões esportivas do bairro. Quinca não o conhecia, o que se tornou uma ótima possibilidade em aproximar os dois moradores, criando uma rede mais descentrada de outras lideranças e protagonistas locais.

Sempre ao final do dia, retornávamos para uma escola onde era nosso alojamento e, após o banho e o jantar, fazíamos as nossas reuniões, primeiro no grupo geral e depois nos pequenos grupos para tratar de assuntos mais operacionais e buscar informações teóricas e práticas na internet, livros e artigos que pudessem nos auxiliar nas ações.

As discussões no grupo geral sempre eram importantes para que as impressões e questionamentos dos que estavam mais distantes servissem de enriquecimento para aquilo que ainda não era compreendido, ampliando as percepções sobre a imersão local. Com isso, as informações das entrevistas foram organizadas e acrescentadas às informações construídas por todo o grupo.

No quarto dia, com as informações organizadas em um pequeno relatório, anexamos, por sugestão de outros companheiros da equipe, imagens de algumas experiências bem sucedidas de projetos de praças e áreas de lazer feitas por organização comunitária, dentro e fora da cidade de Itapeva, e conversamos com Deniro sobre o jovem Dener que havíamos conhecido.

Na manhã seguinte, fomos para a Associação de Moradores para a roda de conversa. Quando chegamos, o quintal da associação estava repleto de gente, homens e mulheres, entre crianças, adultos e idosos. Deniro havia chamado todos para a roda, com a intenção de ter as propostas decididas naquele mesmo dia.

A reunião teve início com a fala de Deniro, apresentando aos moradores a equipe do Projeto Rondon. Logo após, nos passou a palavra e apresentamos os resultados das entrevistas que realizamos e um quadro de possibilidades sobre áreas de lazer. 
Joaquim e Dener se apresentaram aos moradores compartilhando suas experiências em atividades de lazer e esporte no bairro, muitos não sabiam dessas experiências. Foram reconhecidos e aprovados pelos moradores como as duas lideranças para o projeto de lazer. Em seguida, todas as propostas foram levantadas, debatidas ativamente, os tipos de equipamentos de lazer que os moradores gostariam foram elencados em um painel, assim como a dimensão do espaço e o lugar em que seria feito o projeto, que foi denominado "Espaço de Convivência do Jardim Kantian".

Itapeva é uma cidade com forte produção madeireira, e por isso foi levantada a proposta de utilizar madeira reciclável para a construção do parquinho para as crianças, como sugestão a ser feita para a prefeitura. Decidiu-se também que a área de lazer ocuparia um espaço no bairro, que servia até então como área de descarga de lixo (Figura 1), o que implicava sérios problemas à saúde dos moradores.
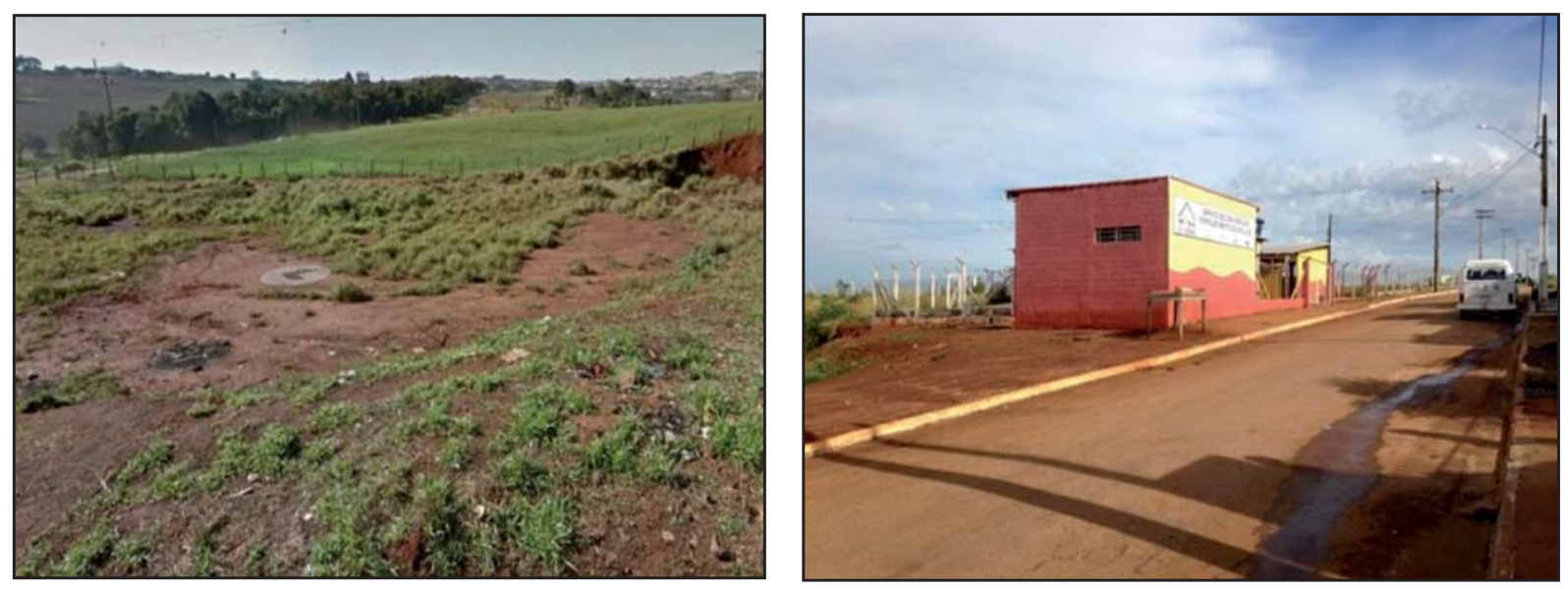

Figura 1 - Espaço para descarte de lixo no Jardim Kantian Fonte: Relatório final Itapeva 04, Doc. 26 (2014).

Ainda nessa mesma reunião, conversamos com a Secretária da Associação de Moradores e com o Deniro sobre a importância de fazerem as Atas das reuniões, pois até então, só havia listas de presenças. Apresentamos a eles um modelo simples de Ata e que poderiam utilizar para agregar não só os valores comunitários como também valor legal.

No dia seguinte, realizamos uma nova reunião na Associação de Moradores com alguns representantes do poder público, que aceitaram participar da roda de conversa junto com os moradores. Compareceram o Secretário Municipal de Esportes com dois assistentes, o Secretário do Meio Ambiente e o vereador que fora citado durante as conversas. O projeto foi apresentado por Deniro.

Os secretários e o vereador conversaram com os moradores sobre as questões de licitação de empresas e os processos burocráticos da Prefeitura. Trouxeram exemplos como o Projeto Família na Praça, iniciativa da Prefeitura de Itapeva, que poderia se adequar ao bairro levando em conta o que os moradores já haviam decidido no dia anterior, respeitando as especificidades do local e as percepções dos moradores como condutores do projeto.

Após estas e outras observações acerca do projeto, nos sentíamos mais à vontade no papel de mediadores, para levantar questionamentos sobre a construção do projeto durante a roda de 
conversa e orientar os participantes sobre pequenas estratégias, como o uso de recursos para a escrita do projeto, organização de calendário, entre outros.

Assim, naquele dia ficou marcada uma nova reunião entre os secretários, Quinca e Dener, para apresentar e discutir o projeto com a secretaria de obras. Incentivamos para que fossem marcadas reuniões periódicas para um bom acompanhamento do projeto e fortalecimento de vínculo com o poder público.

No último dia de nossa atuação local, propusemos um encontro de Quinca e Dener com as crianças do bairro, a fim de que eles pudessem ouvir e conhecer as crianças e seus desejos sobre o brincar e o lazer, além de servir como um fechamento de nossa atuação.

Organizamos algumas atividades recreativas na creche do bairro como brincadeiras livres e jogos de cooperação. Também foram feitas oficinas com recursos gráficos relacionados à horta comunitária e construído um painel sobre as percepções das crianças sobre o bairro no presente e o futuro que gostariam.

Em nossa despedida, acordamos de manter o contato via e-mail, telefone e rede social virtual, para que pudéssemos acompanhar o andamento da construção e efetivação do projeto, nos colocando à disposição para apoiar em estratégias quando fosse necessário. Quinca e Dener seguiram a parceria de acompanhar as ações do projeto de lazer, mantendo as reuniões na Associação de Moradores coordenadas por Deniro.

Pouco mais de quatro meses, no dia 12 de dezembro de 2015, foi inaugurado o Espaço de Convivência e Praça Raul Almeida Barros (em homenagem a um morador falecido) no bairro Jardim Kantian, ocupando a antiga várzea de descarte de lixo (Figura 2). A concretização do espaço expressa não só uma dimensão local de projetos de vida coletiva, como o poder de governança entre seus moradores.
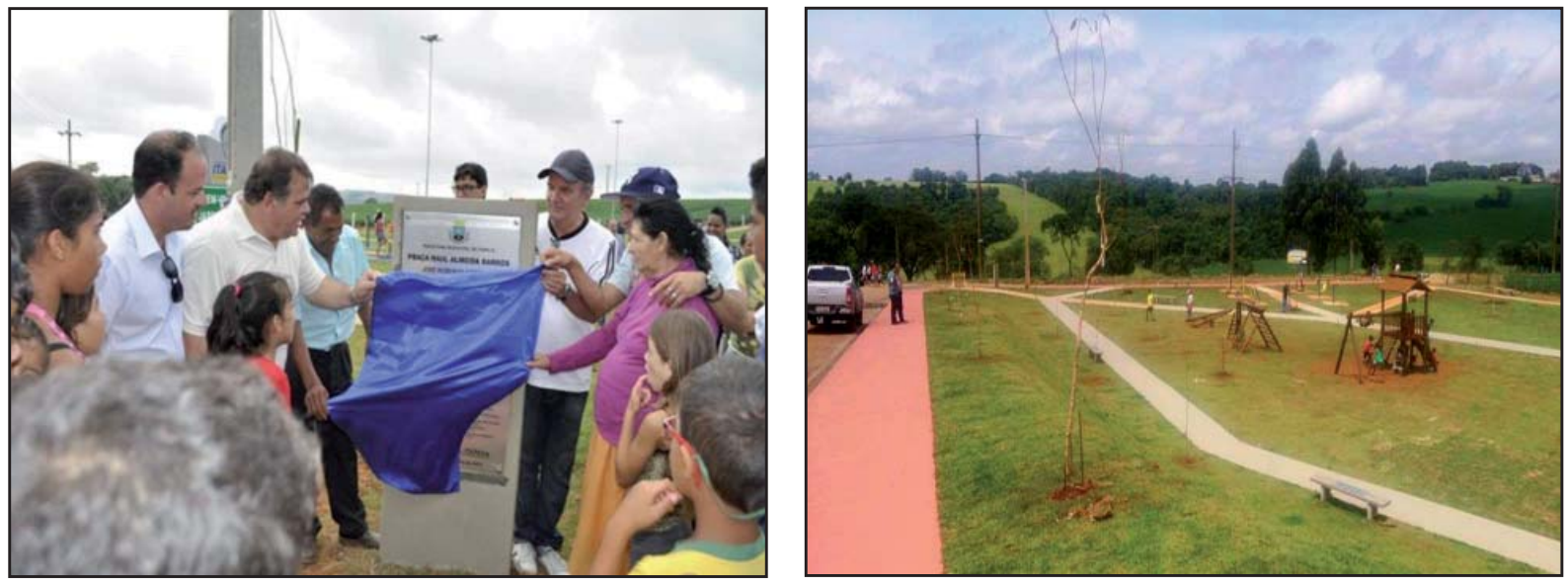

Figura 2 - Espaço de Convivência do Jardim Kantian Fonte: Facebook Prefeitura de Itapeva (2015).

\section{RESULTADOS E DISCUSSÃO: OS CONTEÚDOS DE APREENSÃO DA ENSINAGEM EM DLP E A PRODUÇÃO DO CONHECIMENTO SOBRE AS QUESTÕES DE VIDA LOCAL}

Os processos educativos da participação como a ensinagem em DLP produzem em ato os paradigmas dos modos de se engajar e compartilhar saberes. 
Com isso, o objetivo das ações no Jardim Kantian foi construir junto aos moradores um projeto de vida coletiva, que, segundo Correia e Rocha (2016), expressa e compreende um conjunto de atividades identificadas e eleitas por um coletivo local, que, quando operacionalizado pelos moradores, tendo apoio dos diversos segmentos formais e informais, públicos e privados, contribuem para a criação e fortalecimento de redes de apoio e mecanismo na relação entre estruturas micro e macrossociais.

Ao extrair palavras que nos sugeriam a enunciação dos agentes envolvidos nos modos de apreensão do processo de ensinagem em DLP, a correlação entre elas, segundo Bardin (2016), nos permitiram identificar a triangulação como apontados por Anastasiou e Alves (2004) durante as experiências no Jardim Kantian (quadro 1).

\begin{tabular}{|c|c|}
\hline Categorias de correlação & Conteúdos apreendidos \\
\hline $\begin{array}{l}\text { O processo de ensino- } \\
\text { aprendizagem em ato: fazendo a } \\
\text { aula no contexto local }\end{array}$ & $\begin{array}{l}\text { Equipe geral convidadas pelo professor, mobilizações pessoais, } \\
\text { apreensões do local, debateram em conjunto, criara e propor } \\
\text { estratégias, conteúdos apreendidos, transformações em questões, } \\
\text { projetos de ação, objetivos de nossas ações, questões de lazer do } \\
\text { bairro, primeiro nos grupos gerais e depois nos pequenos grupos } \\
\text { para tratar de assuntos mais operacionais, buscar informações } \\
\text { teóricas e práticas na internet e livros, ampliando a percepção } \\
\text { sobre a imersão. O professor, uma lousa, a chuva de ideias, } \\
\text { Brainstorm, síntese de ideias, reflexão, decisão tomada, estratégias } \\
\text { de entrevistas, explorar percepções entre os moradores, objetivos, } \\
\text { projetos de vida coletiva. }\end{array}$ \\
\hline $\begin{array}{l}\text { Estratégias de imersão e ampliação } \\
\text { da realidade: criação e exploração } \\
\text { de estratégias mútuas }\end{array}$ & $\begin{array}{l}\text { Primeiro contato, informação problema, apresentou o bairro, outros } \\
\text { moradores, vínculos, atividades da vida dos moradores, história do } \\
\text { bairro, imersão, explorar as percepções com os demais moradores, } \\
\text { nossas expectativas, entrevistas domiciliares, tabularíamos } \\
\text { os dados, roda de conversa, compartilhar as informações. } \\
\text { Aproximando pessoas, conversar, mobilizar as pessoas, propostas } \\
\text { de estratégias, convidar o poder público, relatório, resultados } \\
\text { das entrevistas, intenção, decisões, quadro de possibilidades, } \\
\text { discutissem experiências locais, debate ativo, Atas de reuniões, } \\
\text { agregar valores, inserção do poder público, especificidades da } \\
\text { cultura local, responsabilidades e responsáveis pelas questões. }\end{array}$ \\
\hline $\begin{array}{l}\text { Percepções sobre os papéis } \\
\text { construídos: habilidades e } \\
\text { competências }\end{array}$ & $\begin{array}{l}\text { Papel de mediadores, levantar questionamentos, manutenção de } \\
\text { contatos, acompanhar o andamento da construção, apoiar em } \\
\text { estratégias em comunidade, contexto de inserção, consciência } \\
\text { enquanto equipe, apoio e mediação dos processos, construção } \\
\text { de projetos coletivos, apoiar a criação de atividades, estratégias } \\
\text { participativas, construção de raciocínio, tomadas de decisões junto } \\
\text { aos moradores. Sentimo-nos mais próximos, confiança e parceria de } \\
\text { trabalho. }\end{array}$ \\
\hline $\begin{array}{l}\text { Efeitos das estratégias: o conteúdo } \\
\text { próprio das questões de vida local. }\end{array}$ & $\begin{array}{l}\text { Percepções informadas, queriam lazer, gostariam, desejavam, } \\
\text { todos os moradores contemplados, espaço com função social, } \\
\text { ampla integração com as pessoas, primeira experiência, construção } \\
\text { comunitária, questões percebidas com organização, Associação } \\
\text { de Moradores, discursos diferentes, compartilhar estratégias e } \\
\text { saberes, mudar as concepções, ouvir a opinião, ajudar, melhorias } \\
\text { para o bairro, intervenção direta dos moradores, fragilidade e } \\
\text { fortalecimento da participação, efetivação do projeto. }\end{array}$ \\
\hline
\end{tabular}

Quadro 1 - Análise de correlação entre os conteúdos de apreensão da ensinagem em DLP Fonte: dos autores 
Tabuladas as enunciações e suas correlações em unidades de conteúdo, extraímos uma matriz sócio-histórica, como propõe Pimentel (2001). Estas tratam sobre apreensão de conteúdos das questões de vida local como um eixo sustentador do processo de triangulação da ensinagem em desenvolvimento local participativo.

Em seguida, as unidades foram tomadas como orientadoras de uma nova leitura dos documentos e do texto narrativo produzido, a fim de validar suas informações. Feito isso, extraímos duas categorias de análise que denominamos de (a) "Processo de ensinagem em desenvolvimento local participativo para a desconcentração de capitais" e (b) "A produção de novas epistemologias a partir dos encontros".

\subsection{Processo de ensinagem em desenvolvimento local participativo para a desconcentração de capitais e a produção de comunidades}

A criação de processos de participação entre pessoas em âmbito local, de forma que estas possam usar e ampliar suas habilidades nas transformações da realidade, convertendo-as em capacidades, expressam modificações na dimensão "glocal" (SOMEKH, 2008), pois produzem capitais sociais e humanos para criar trajetórias de vida que possibilitam o desenvolvimento de liberdades (SEN, 2000).

Os estudantes desempenharam o papel de mediadores ao invés do tradicional papel de consultores e palestrantes atribuídos aos representantes acadêmicos, concentradores de saberes e poderes globais. Não havia conteúdos prévios e sim, conteúdos in loco que foram apreendidos como conhecimento quanto mais se construíam atitudes estratégicas, sendo essas atitudes um importante conjunto de apreensão do conhecimento para operacionalizar os processos em DLP.

A desconcentração de saberes e de poderes na dimensão local, para Somekh (2008), precisa ser feita a partir do reconhecimento e produção compartilhada entre diversos segmentos locais.

Um grupo não leva a cabo os seus projetos de vida coletiva somente pela dimensão de seus desejos e força de vontade, fazendo-se necessária a construção e articulação de uma rede de agentes que ofereçam entre si possibilidades de acesso e outras formas de se colocar, em debate e ação, seus desejos e questões.

A eficácia de projetos que atendam às expectativas de todos os segmentos envolvidos em um grupo é, necessariamente, o engajamento contínuo e consciente em suas ações, uma vez que nem sempre as metas traçadas serão efetivamente concretizadas, pois são interdependentes de campos de forças convergentes e divergentes.

No entanto as estratégias em processo e o engajamento ativo permitem a tomada e ampliação de consciência crítica e o sentido que estes têm, enquanto produção de novos capitais sociais, para desconcentrar outros capitais que impossibilitam o desenvolvimento local.

Quando Sen (2000) propõe uma teoria que enfoca as capacidades, nesses registros verificamos que quanto mais se produzia uma rede de compartilhamento em torno do projeto de vida coletiva de lazer, mais as habilidades eram convertidas em capacidades, pois a formação de redes, como argumentam Marteleto e Silva (2004), vão se tornando dispositivos de mediação entre as estruturas e dinâmicas micro e macrossociais.

Os processos de aproximação e diálogo entre moradores e poder público expressaram significativamente a produção das redes e os sentidos de comunidade gerados enquanto efeitos da ensinagem em DLP. 
Para Souza (1987) esse tipo de engajamento em rede produz temporal ou permanentemente fluxos e sentidos de comunidade. Não como um elemento dado, presente permanentemente como uma área geográfica, mas que se organiza enquanto evento, um ato, um dispositivo para levar a cabo os anseios que só podem se dar em função da participação em um coletivo.

Identificar os elementos da realidade, debater, negociar, ensinar e aprender, produzir junto e reconhecer-se produtor de um saber crítico local foram os marcadores expressos e apreendidos na rede do Jardim Kantian, tornando-se conteúdos de conhecimento que permearam as relações de contratualidade entre os agentes locais, gerando estados de governança e efeitos na realidade concreta (SOMEKH, 2008):

Para Marteleto e Silva (2004), essas competências correspondem à produção e uso de capital social, que servem para promover o desenvolvimento local e o bem-estar social em todas as suas dimensões.

Com confiança, o projeto construído junto aos moradores do Jardim Kantian, expressa concreta e objetivamente fluxos e sentidos de comunidade (SOUZA, 1987; COSTA, 2008) como um efeito de colocar em ato a desconcentração de capitais.

\subsection{A produção de novas epistemologias a partir dos encontros}

O deslocamento dos processos de fazer a aula, segundo Anastasiou (1998), permitiu criar e explorar estratégias, assim como apreender conteúdos em sua forma própria em torno das questões de vida local.

Verificamos que a abordagem em DLP foi uma metodologia ativa com função educativa (CORREIA; ROCHA, 2016; CORREIA; AKERMAN, 2015; FÉLIX et al., 2009; ÁVILA, 2000), uma vez que o seu paradigma da participação orientou a triangulação, extrapolando a relação professor-estudantes e inserindo os agentes locais como figuras indissociáveis desse processo.

Para Silveira e Ribeiro (2005), o encontro e envolvimento entre pessoas, como destacados nas estratégias das rodas de conversa, tornam-se mecanismos essenciais de ensinagem para a construção de projetos de enfrentamento das questões da vida, pois se compartilham nesse jogo experiências e saberes, assim como, formas de encorajamento para o enfrentamento das vulnerabilidades.

É importante que um coletivo local sinta-se capaz de conhecer criticamente sua realidade e encontrar endogenamente os mecanismos para resolvê-las.

Esses processos foram identificados no projeto do Jardim Kantian como produção de uma epistemologia local, a partir do encontro entre universidade (agente externo) e outros segmentos da sociedade (agentes locais - sociedade civil e poder público). O deslocamento acadêmico de estudantes de graduação para o contexto local, procurou não tomar a realidade como mero objeto de estudo, ,mas sim apreender seus conteúdos próprios e significativos enquanto questões de vida local, modificando tanto os paradigmas científicos como os agentes envolvidos.

O espaço para debater e refletir as questões de vida local é uma estratégia que gera pensamento-ação-pensamento, como argumenta Anastasiou (1998), e, portanto, o que se produz enquanto conhecimento é de fato um profundo envolvimento de sujeitos nas questões de sua realidade local. E que mais crítica torna-se, quando apreendida pelas expressões de estruturas e dinâmicas mais ampliadas. 
Com isso, a produção de comunidade, enquanto um conhecimento sobre as questões de vida local neste projeto, nos leva à compreensão, como argumenta Bourdieu (2004), de que o desenvolvimento de novas epistemologias é possível quando no engajamento e imersão na realidade, superando e transformando as representações objetificadas das Ciências, em particular a grupos estigmatizados socialmente.

\section{CONCLUSÃO}

Compreendemos que as apreensões sobre questões de vida local se dão pelos efeitos observados no deslocamento de estruturas de saberes, entre agentes externos e internos, em determinada dimensão local, o que passa a oferecer pistas para a apreensão de um processo de ensinagem em desenvolvimento local participativo.

A construção do projeto de lazer do Jardim Kantian foi uma dimensão, ou um recorte possível e concretizado, daquilo que compreendemos como expressões do "glocal", e que, portanto, disparou e expressou as questões de vida local como um conteúdo mútuo do conhecimento, entre forças micro e macrossociais, produzindo endogenamente mecanismos para o seu enfrentamento.

Esse conhecimento, apreendido a partir da triangulação da ensinagem em desenvolvimento local participativo, é compreendido enquanto comunidades, um processo contínuo de construção de redes interpessoais que possibilitam a criação e exploração de estratégias, capacidades, suportes e liberdades para os projetos de vida coletiva.

Com isso, esta pesquisa sugere um caminho possível para lidar com as demandas cada vez mais complexas do tecido social, que podem ser operacionalizadas por meio de processos participativos da vida coletiva.

\section{AGRADECIMENTO}

A Deniro, in memoriam.

\section{REFERÊNCIAS}

AKERMAN, M. Saúde e desenvolvimento local: princípios, conceitos, práticas e cooperação técnica. São Paulo: Hucitec, 2005.

ANASTASIOU, L. G. C. Profissionalização continuada do docente da educação superior: desafios e possibilidades. Olhar de Professor, Ponta Grossa, PR, v. 8, n. 1, p. 9-22, 2005.

ANASTASIOU, L. G. C. Metodologia do Ensino Superior: da prática docente a uma possível teoria pedagógica. Curitiba: IBPEX, 1998.

ANASTASIOU, L. G. C.; ALVES, L. P. (Org.). Processos de ensinagem na universidade: pressupostos para as estratégias de trabalho em aula. 5. ed. Joinville, SC: UNIVILLE, 2005.

ÁVILA, V. F. "Paciência", capitalismo, socialismo e desenvolvimento local endógeno. Interações, Campo Grande, MS, v. 9, n. 1, p. 85-98, jan./jun. 2008.

ÁVILA, V. F. Pressupostos para a formação educacional em Desenvolvimento Local. Interações, Campo Grande, MS, v. 1, n. 1, p. 63-76, set. 2000.

BARDIN, L. Análise de conteúdo. São Paulo: Edições 70, 2016.

BARROS, M. B. B.; EL-DEIR, S. G. Desenvolvimento local participativo - uma cidade pensada como campo educativo e de participação. Revista Transformar ADM, São Paulo, v. 1, n. 2, 2012. 
BOURDIEU, P. Os usos sociais da ciência: por uma sociologia clínica do campo científico. São Paulo: Editora UNESP, 2004.

COSTA, S. L. Os sentidos da comunidade: construções intergeracionais de memória coletiva na ilha de caieiras, em Vitória, ES. 337fl. Tese (Doutorado em Psicossociologia de Comunidades e Ecologia Social) Instituto de Psicologia, Universidade Federal do Rio de Janeiro, Rio de Janeiro, 2008.

CORREIA, R. L.; AKERMAN, M. Desenvolvimento local participativo, rede social de suporte e ocupação humana: relato de experiência em projeto de extensão. Revista de Terapia Ocupacional da Universidade de São Paulo, São Paulo, v. 26, n. 1, p. 159-165, 2015.

CORREIA, R. L.; ROCHA, C. S. Ordem cultural e desenvolvimento local participativo: estrutura para a prática do terapeuta ocupacional. Cadernos de Terapia Ocupacional da UFSCar, São Carlos, SP, v. 24, n. 1, p. 205-216, 2016.

FÉLIX, W. J. S; QUIRINO, R. H. R.; GRANJEIRO, R. R.; SILA JR., J. T. A relação entre tecnologia social e o desenvolvimento local participativo: a Apaeb e o Instituto Palmas como expressão destes vínculos. Revista ADM/MADE, ano 9, v. 13, n. 2, p. 16-33, maio/ago. 2009.

FREIRE, P. Extensão ou Comunicação? 15. ed. São Paulo: Paz e Terra, 2011.

FÓRUM DE PRÓ-REITORES DE EXTENSÃO DAS UNIVERSIDADES PÚBLICAS BRASILEIRAS (FORPROEX). Política Nacional de Extensão Universitária. 2-4 maio 2012, Manaus. Anais... Manaus: FORPROEX, 2012.

ITAPEVA, Cidade [de]. Doc. 27, de 6 jul. 2015. Relatório Final - Itapeva 07: "todas as estratégias devem envolver a comunidade e o poder público". Itapeva: FMABC; PUCSP; UMESP; UNISA; UFRJ. In: CORREIA, R. L. Processos de ensinagem em desenvolvimento local participativo: a articulação comunitária e a produção do conhecimento fronteiriço enquanto capital social. Tese (Doutorado em Ciências da Saúde) - Faculdade de Medicina do ABC/Fundação do ABC, Santo André, SP, 2017.

MARTELETO, R. M.; SILVA, A. B. O. Redes e capital social. O enfoque da informação para o desenvolvimento local. Ciência da Informação, Brasília, v. 33, n. 3, p. 41-49, set./dez. 2004.

MORAIS, J. A.; CALLOU, A. B. F. Metodologias participativas e desenvolvimento local: a experiência do projeto Dom Hélder Câmara no assentamento Moacir Lucena. Interações, Campo Grande, MS, v. 18, n. 1, p. 165-177, jan./mar. 2017.

PIMENTEL, A. O método da análise documental: seu uso numa pesquisa historiográfica. Cadernos de Pesquisa, v. 2, n. 114, p. 179-195, 2001.

RIBEIRO, A. C. T. O desenvolvimento local e a arte de "resolver" a vida. In: LIANZA, S.; ADDOR, F. Tecnologia e desenvolvimento social e solidário. Porto Alegre: Editora da UFRGS, 2005.

SAPPI, J. C. A participação do exército brasileiro no Projeto Rondon. 2006. Monografia (Especialização em Política, Estratégia e Alta Administração Militar) - Escola de Comando e Estado-Maior do Exército, Rio de Janeiro, RJ, 2006.

SEN, A. Desenvolvimento como liberdade. São Paulo: Cia. das Letras, 2000.

SILVEIRA, L. M. C.; RIBEIRO, V. M. B. Grupo de adesão ao tratamento: espaço de "ensinagem" para profissionais de saúde e pacientes. Interface - Comunicação, Saúde, Educação, Botucatu, SP, v. 9, n. 16, p. 91-104, 2005.

SOMEKH, N. Construção social da cidade: desenvolvimento local e projetos urbanos. In: DOWBOR, L.; POCHMANN, M. Políticas para o desenvolvimento local. São Paulo: Editora Fundação Perseu Abramo, 2008.

SOUZA, M. L. O desenvolvimento de comunidade e participação. São Paulo: Cortez, 1987.

VALLADARES, L. P. A invenção da favela: do mito de origem a favela.com. Rio de Janeiro: Editora FGV, 2005. 


\section{Sobre os autores:}

Ricardo Lopes Correia: Terapeuta Ocupacional. Doutor e Mestre em Ciências da Saúde/concentração em Saúde Coletiva, Politicas Públicas e Determinantes Sociais. Especialista em dependências, abusos e compulsões. Professor do Departamento de Terapia Ocupacional da Faculdade de Medicina da Universidade Federal do Rio de Janeiro (UFRJ).E-mail: toobiis@gmail.com

Samira Lima da Costa: Professora Adjunta IV do Departamento de Terapia Ocupacional da UFRJ e do Programa de Pós-Graduação em Psicossociologia de Comunidades e Ecologia Social da UFRJ. Possui graduação em Terapia Ocupacional, especialização em Saúde Pública e mestrado em Educação pela Universidade Federal de São Carlos (UFSCar), doutorado em Psicossociologia de Comunidades e Ecologia Social pela Universidade Federal do Rio de Janeiro (UFRJ). E-mail: biasam2000@gmail.com

Marco Akerman: Professor Titular do Departamento de Prática de Saúde Pública da Faculdade de Saúde Pública da Universidade de São Paulo (USP). Médico e especialista em Saúde Pública e Medicina Social pela Universidade Federal de Minas Gerais (UFMG); especialista em Gestão Hospitalar para o Setor Público pela Fundação Getúlio Vargas (FGV); mestre em Planejamento e Financiamento do Setor de Saúde e PhD em Epidemiologia e Saúde Pública, pela Universidade de Londres; especialista em Ativação de Mudanças na Graduação de Profissionais de Saúde pela Fundação Oswaldo Cruz (FIOCRUZ); Livre-Docente pela Faculdade de Saúde Pública da USP. Faculdade de Saúde Pública da Universidade de São Paulo. Faculdade de Medicina do ABC.

E-mail:marco.akerman@gmail.com 
